\title{
Observations of decomposition of martensite during heat treatment of steels using atom probe tomography
}

\author{
E.V. Pereloma ${ }^{\mathrm{a} 1}$, S.P. Ringer ${ }^{2}$, I.B. Timokhina ${ }^{3}$ and P.D. Hodgson ${ }^{3}$ \\ ${ }^{1}$ School of Mechanical, Materials and Mechatronic Engineering, University of Wollongong, NSW 2522, \\ Australia \\ ${ }^{2}$ Australian Key Centre for Microscopy \& Microanalysis, The University of Sydney, NSW 2006 Australia \\ ${ }^{3}$ Centre for Material and Fibre Innovation, Deakin University, Geelong, VIC 3127, Australia
}

\begin{abstract}
The decomposition of martensite during tempering or ageing is an important phenomenon as it leads to changes in the mechanical properties. These changes could take place during both steel manufacturing or in-service. Thus, their understanding is required to predict the material performance. Recent advances in the development of local electrode atom probes has led to a significant increase in the analysed volume of material (up to 100 millions of atoms) and at the same time reduced the acquisition times. This allows improvement in data statistics when investigating fine nanoscale features, such as solute segregation, clustering and ultrafine precipitation. Selected results of atom probe studies on the decomposition of martensite from bake hardening of a pre-strained Transformation Induced Plasticity (TRIP) steel and ageing of FeNiTiMnAl maraging steel are presented.
\end{abstract}

\section{Introduction}

Recent developments of local electrode atom probes [1-3] open new opportunities for analysis of martensite decomposition at the atomic level. These modern instruments allow the collection of data in a shorter period of time from a larger volume of material compared to the previous generation atom probe field ion microscopes. As a result, a more accurate and statistically better analysis of chemical composition, shape and distribution of fine microstructural features present in the material, such as nanoscale precipitates and clusters, is achieved.

For decades, the decomposition of martensite in various steel grades has attracted the attention from both fundamental and applied perspectives. This process leads to modification of the mechanical properties, which could have both beneficial and negative effects depending on the stage of martensite decomposition and the desirable in-service characteristics of the material. Whereas, there is a general agreement on the stages of decomposition taking place during tempering of carbon-containing ferrous martensite [4,5], some discrepancies still exist on the nature of the initial carbides formed. However, the atom probe tomography not only provides insight into the early stages of clustering in martensite, but also highlight the details of the precipitation sequence at a later stage.

Transformation-induced plasticity (TRIP) steels are promising candidates for applications in the automotive industry [6-9]. After forming, the automotive body is subjected to a paint baking process (typically for 20 minutes at $175-180^{\circ} \mathrm{C}$ ), which results in an additional strength increase [7-9]. The microstructure of the TRIP steels consists of polygonal ferrite, carbide-free bainite morphologies, retained austenite and martensite. As previous studies using electron microscopy have shown [9-13], during pre-straining and bake hardening various microstructural changes take place: increase in dislocation density, especially in polygonal ferrite in the vicinity of hard martensite or retained austenite crystals, strain-induced transformation of austenite to martensite and precipitation of fine carbides in the bainitic ferrite.

FeNiTi (Mn,Al) maraging steels exhibit an unusual rapid hardening phenomenon after just $5 \mathrm{~s}$ ageing at $550^{\circ} \mathrm{C}$ [14-17]. In this condition it achieves approximately $50 \%$ of the maximum increase in strength without significant sacrifices in ductility. Based on the transmission electron microscopy data, there is no indication of precipitate formation during ageing times below $60 \mathrm{~s}$. Thus, atom probe tomography is the most suitable technique to elucidate the decomposition of martensite in this steel.

\footnotetext{
a e-mail: elenap@uow.edu. au
}

This is an Open Access article distributed under the terms of the Creative Commons Attribution-Noncommercial License (http://creativecommons.org/licenses/by-nc/3.0/), which permits unrestricted use, distribution, and reproduction in any noncommercial medium, provided the original work is properly cited. 
In this paper we present selected atom probe studies on decomposition of martensite during bake hardening of the TRIP steel, subjected initially to thermomechanical processing, and on the ageing behaviour of Fe-Ni-Mn-Ti-Al maraging steel.

\section{Experimental}

\subsection{TRIP steel}

The compositions and selected processing parameters for the studied TRIP steel are given in Table 1. It was subjected to thermomechanical processing simulation using a laboratory rolling mill at Deakin University. The details of the processing schedule are described elsewhere [13]. After the simulation of coiling in a fluidized bed furnace, the samples were quenched to room temperature. Tensile specimens were machined from the strip and subjected to $4 \%$ pre-straining (PS) before bake hardening (BH) at $175^{\circ} \mathrm{C}$ for $60 \mathrm{~min}$.

Table I. TRIP steel compositions and thermomechanical processing parameters

\begin{tabular}{|c|c|c|c|c|c|c|c|c|c|c|c|c|}
\hline \multirow{2}{*}{\multicolumn{2}{|c|}{ Steel }} & \multicolumn{8}{|c|}{ Element } & \multicolumn{3}{|c|}{ Parameters } \\
\hline & & $\mathrm{C}$ & $\mathbf{S i}$ & Mn & Mo & Al & $\mathbf{C u}$ & $\mathbf{N b}$ & $\mathbf{P}$ & $\mathrm{T}_{\mathrm{AC} \cdot}{ }^{\circ} \mathrm{C}$ & $\mathrm{T}_{\mathrm{IH}},{ }^{\circ} \mathrm{C}$ & $\mathbf{t}_{\mathrm{IH}}, \mathrm{s}$ \\
\hline \multirow{2}{*}{$\mathbf{A R}$} & $w t \%$ & 0.21 & 1.18 & 1.52 & 0.29 & 0.57 & 0.03 & 0.036 & 0.027 & \multirow{3}{*}{780} & \multirow{3}{*}{450} & \multirow{3}{*}{1200} \\
\hline & at $\%$ & 0.95 & 2.3 & 1.51 & 0.16 & 1.15 & 0.026 & 0.02 & 0.05 & & & \\
\hline $\begin{array}{l}\text { M- } \\
\text { BH }\end{array}$ & at $\%$ & $\begin{array}{c}1.5 \\
\pm 0.07\end{array}$ & $\begin{array}{c}3.7 \\
\pm 0.1\end{array}$ & $\begin{array}{c}1.11 \\
\pm 0.06\end{array}$ & 0 & $\begin{array}{c}1.64 \\
\pm 0.07\end{array}$ & $\begin{array}{c}0.07 \\
\pm 0.02\end{array}$ & $\begin{array}{c}0.06 \\
\pm 0.01\end{array}$ & $\begin{array}{c}0.03 \\
\pm 0.01\end{array}$ & & & \\
\hline
\end{tabular}

Fe is balance. AR-as-received, $\mathrm{M}-\mathrm{BH}$ - martensite after bake hardening, $\mathrm{T}_{\mathrm{AC}^{-}}$accelerated cooling start temperature; $\mathrm{T}_{\mathrm{IH}^{-}}$ isothermal hold temperature, $\mathrm{t}_{\mathrm{IH}}$-holding time

Atom probe tomography (APT) studies were carried out using the Oxford nanoScience 3DAP at the Monash Centre for Electron Microscopy. The pulse repetition rate was $20 \mathrm{kHz}$ and the pulse fraction was 0.2 . The sample temperature was $60 \mathrm{~K}$.

\subsection{Maraging steel}

An experimental steel with the following composition: Fe-20.1Ni-1.8Mn-1.6Ti-0.59Al-0.04Si-0.01C with P and $\mathrm{S}<0.001$ (wt $\%$ ) was solution heat treated at $1100^{\circ} \mathrm{C}$ for $12 \mathrm{~h}$. Thin slices of $\sim 0.4 \mathrm{~mm}$ thickness were then cut and solution treated for $1 \mathrm{~h}$ at $1050^{\circ} \mathrm{C}$. To complete the martensite transformation after water quenching the slices were immersed in liquid nitrogen for 10 minutes. Ageing was carried out in salt bath out at $550^{\circ} \mathrm{C}$. Detailed description of processing is given elsewhere [17]. Selected samples, which corresponded to the conditions of the best combination of strength and ductility ( $5 \mathrm{~s}$ ageing) and to the peak strength $(600 \mathrm{~s})$, were chosen for atom probe analysis. Data was acquired from a needle-shape sample inserted into a local electrode atom probe at the University of Sydney operating at a pulse repetition rate of $200 \mathrm{kHz}$, a pulse fraction of 0.2 , and a sample temperature of $80 \mathrm{~K}$.

\subsection{Atom probe data analysis}

A detailed analysis of clusters and fine precipitates was carried out using the maximum separation envelope method [18] with a maximum separation distance between atoms of interest of $0.5 \mathrm{~nm}$ and a grid spacing of 0.1 $\mathrm{nm}$. In order to minimise random solute fluctuations in the matrix, a minimum of 20 atoms was used to define the clusters. Their atomic composition was calculated from the number of atoms of each type forming a cluster or a particle as determined by the maximum separation envelope method. However, it should be noted that the maximum separation method aggressively removes the solvent atoms from particles and clusters, especially from the surface regions. Thus, using this method the solute content of the finest clusters $(\leq 1 \mathrm{~nm})$, in which there is a high proportion of surface to interior atoms, may be overestimated by $\sim 25 \%$. Using the data from the maximum separation method, the observed clusters and fine particles were grouped together based on the selection of nonoverlapping ranges for their solute content. As output of the program, the size of the feature of interest is given by the radius of gyration $\left(1_{\mathrm{g}}\right)$, which is slightly smaller than its actual physical extent. The real size might be better represented by the Guinier radius $\left(\mathrm{r}_{\mathrm{G}}\right)$ given by the following equation [18]:

$$
r_{G}=\sqrt{\frac{5}{3}} \times 1_{g}
$$


The compositions of relatively large precipitates and of the matrix volumes free of visible clusters or precipitates were determined from the selected volumes with background noise subtraction based on the number of atoms. Concentration profiles were taken perpendicular to the interface of the feature of interest. Isoconcentration surfaces were also used to visualize the microstructural features.

\section{Results and Discussion}

\subsection{Effect of bake hardening on martensite in TRIP steel}

After TMP the multi-phase microstructure of TRIP steel consists of $15 \pm 3 \%$ of polygonal ferrite, $16.5 \pm 3 \%$ of retained austenite, $\sim 65 \pm 3 \%$ of carbide-free bainite and the remainder martensite. As previous transmission electron microscopy studies have shown $[10,13]$, the martensite was present in the form of thin layers between the bainitic ferrite laths or in a blocky form as part of the martensite/austenite constituent. However, it should be noted, that at the test temperature of atom probe studies all retained austenite was deemed to be also transformed to martensite. During cooling of strip to room temperature, some of the retained austenite crystals present in the microstructure, which are either chemically or mechanically unstable, transform to martensite. As previous research has shown, this martensite auto-tempers with the formation of fine (20-50 atoms) C-rich clusters $[12,19]$. Additionally, strain-induced martensite forms during pre-straining [9,13]. All of these types of martensite crystals undergo tempering during bake hardening.

The non-uniform segregation of $\mathrm{C}$ atoms is clearly visible in the atom map shown in Fig. 1a. The clusters

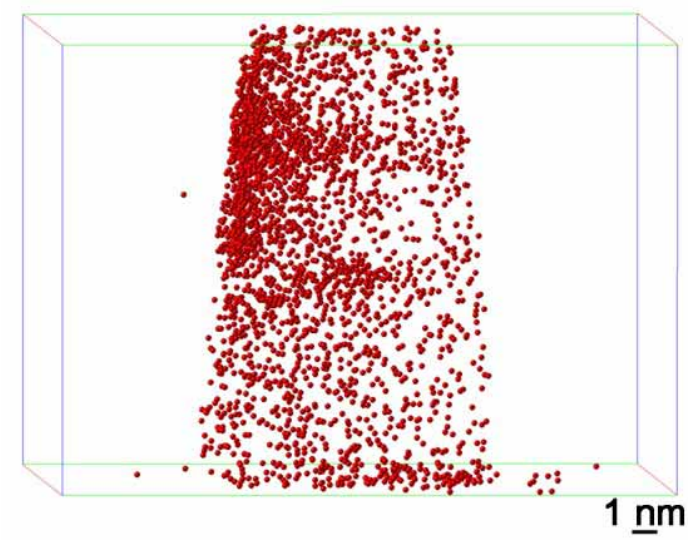

a)

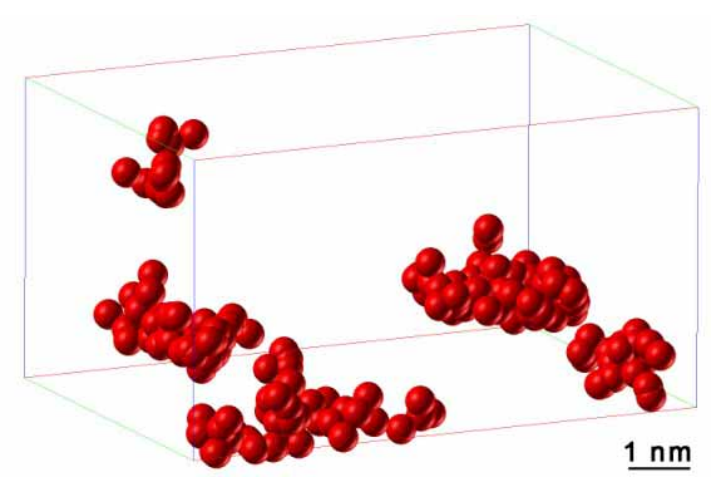

c)

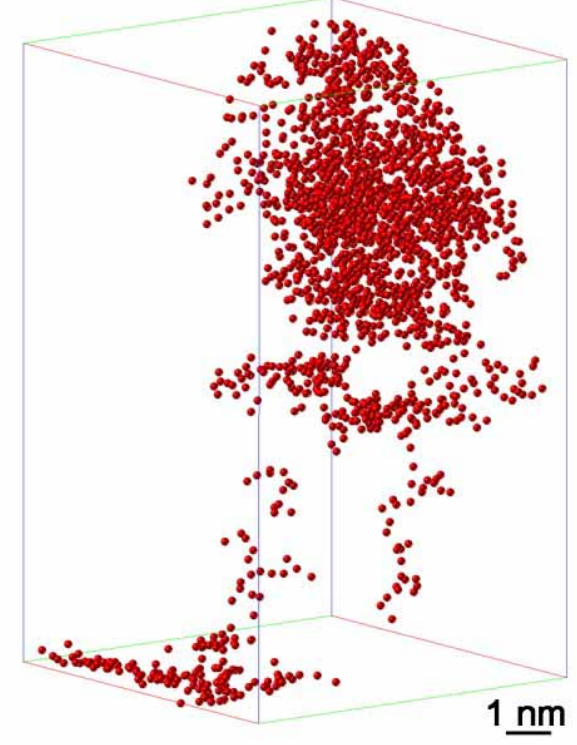

b)

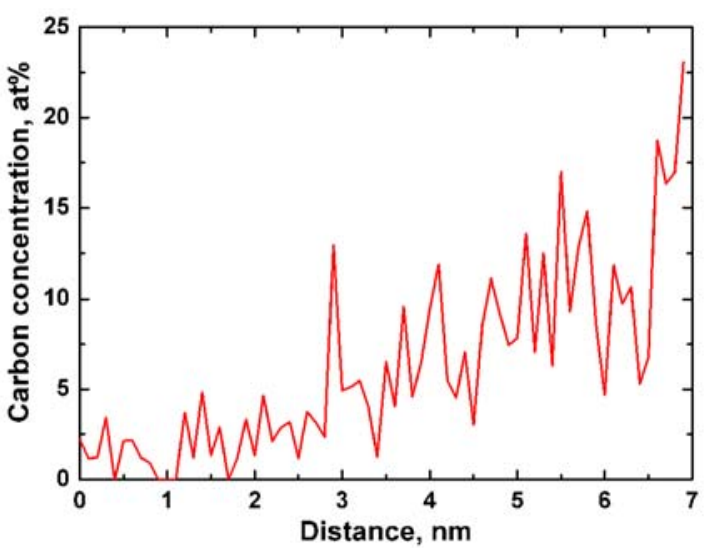

d)

Fig. 1. C atom map (a), clusters (b and c) and representative $C$ concentration profile across matrix/carbide interface (d) in the martensite of TRIP steel after bake hardening. All other atoms are removed in (b) and (c) by the maximum separation envelope method. 
determined by the maximum distance separation method are shown in Fig. $1 \mathrm{~b}$ from different points of view in order to give a better insight into the morphology of the clusters/fine carbides. An enlarged selected area with clusters is shown in Fig. 1c. The concentration profile indicates that the carbon concentration within the coarse carbide reaches approximately $20 \mathrm{at} \%$. The summary of the clusters composition and sizes are given in Table 2 .

It is clear that the fine clusters are predominantly C-rich, as expected and in agreement with the results obtained for the early stages of martensite decomposition in the TMP condition [12]. They do not have the composition of $\mathrm{Fe}_{4} \mathrm{C}$, as suggested by Sherman et.al. [20], but are close to the composition of $\mathrm{FeC}_{8}$. The density of clusters and fine precipitates is an order of magnitude higher than in the martensite after TMP [19,21]. With an increase of cluster/precipitate size, the $\mathrm{C}$ content decreases and the coarsest precipitates reach the composition of $\mathrm{Fe}_{4} \mathrm{C}$. It is surprising that it is not the equilibrium composition of $\mathrm{Fe}_{3} \mathrm{C}$, as was previously observed for several bake-hardened TRIP steels. It could be assumed that due to the limited volume of material analysed in this case the $\mathrm{Fe}_{3} \mathrm{C}$ was not detected. However, the coarse precipitates, visible under TEM, were of that composition $[13,21]$. It is also worth noting, that the matrix composition of martensite (Table I) still shows a significant supersaturation in carbon, indicating that decomposition has not yet been completed. This is in agreement with other studies on the tempering of martensite using APT [21]. Based on the combined body of knowledge to-date, it can be concluded that a continuous set of iron carbide compositions from $\mathrm{C}$-rich clusters to $\mathrm{Fe}_{3} \mathrm{C}$ carbides is present in the tempered martensite.

Table II. Characterisation of clusters and carbides in the martensite of TRIP after bake hardening

\begin{tabular}{|c|c|c|c|c|l|}
\hline \multicolumn{6}{|l|}{ Composition, at\% (AP) } \\
\hline C & Mo & Nb & Fe & $\boldsymbol{r}_{\mathbf{G}}, \mathbf{n m}$ & No. ions per feature \\
\hline $89.4 \pm 5.3$ & - & - & $8.1 \pm 4.8$ & $1.1 \pm 0.1$ & $28 \pm 6$ \\
\hline $51.5 \pm 2.9$ & $3.0 \pm 0.6$ & $1.9 \pm 0.7$ & $26.8 \pm 2.4$ & $3.1 \pm 0.5$ & $302 \pm 42$ \\
\hline $19.7 \pm 0.3$ & $0.3 \pm 0.1$ & $0.3 \pm 0.1$ & $74.0 \pm 0.4 *$ & $4.8 \pm 0.5$ & $11255 \pm 230$ \\
\hline
\end{tabular}

*Traces of Mn and other elements

\subsection{Decomposition of martensite in maraging steel}

Analysis of the sample after $5 \mathrm{~s}$ ageing has clearly shown the solute segregation in the martensite crystals. Al, Ti and $\mathrm{Mn}$ atom maps (Fig. 2) depict the cluster formation. A more detailed analysis using the maximum separation envelope method has shown the preferential formation of $\mathrm{Ti}+\mathrm{Al}$ and $\mathrm{Mn}+\mathrm{Fe}$ clusters (Table III).

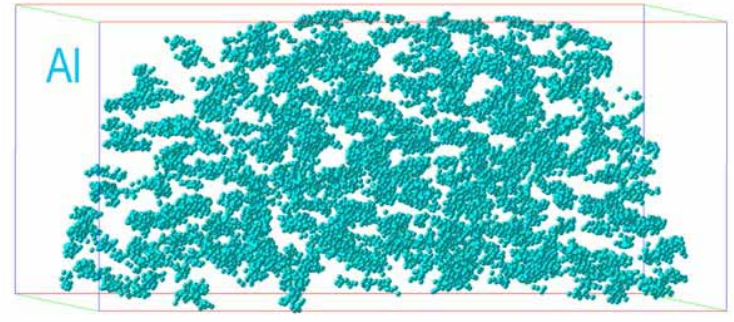

a)

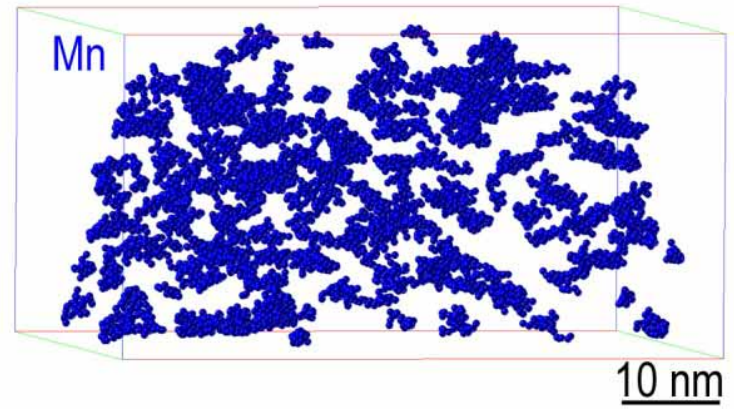

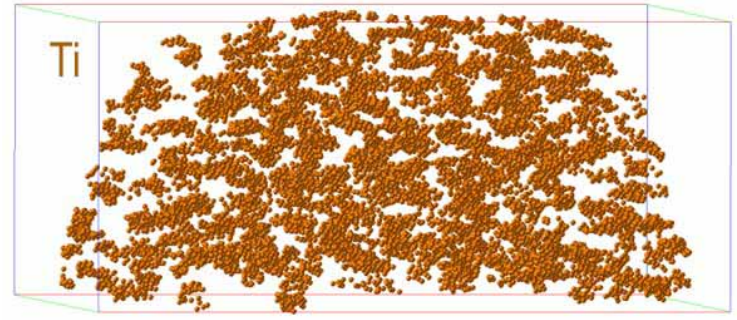

b)

Fig. 2. Cluster formation in FeNiTiAl maraging steel after $5 \mathrm{~s}$ ageing at $550^{\circ} \mathrm{C}$. All other atoms have been removed by the maximum separation method with $\mathrm{d}_{\max }=0.5 \mathrm{~nm}$.

Whereas the composition of Mn-Fe clusters varies, their size remains constant. Contrarily, with an increase in size, $\mathrm{Ti}+\mathrm{Al}$ clusters become richer in $\mathrm{Fe}$ and $\mathrm{Ni}$, which could be explained by the deficiency of the maximum separation method, as described in section 2.3. However, there is no doubt in affinity between $\mathrm{Mn}-\mathrm{Fe}$ and Ti-Al atoms, which results in the formation of these clusters. This is in agreement with the previous Mössbauer spectroscopy data on preferential formation of Fe-Mn bonds and displacement of Ti by Mn from solid solution, 
which leads to the accelerated precipitation of $\mathrm{Ni}_{3} \mathrm{Ti}$ [15]. Mn also has a strong affinity with $\mathrm{Al}$ [22] and with the progress of ageing the formation of nearly spherical $(\mathrm{Fe}, \mathrm{Ni})_{3}(\mathrm{Mn}, \mathrm{Al})$ particles was observed (Fig. 3). It could be suggested that not only dislocations, but Fe-Mn clusters, served as heterogeneous nucleation sites for these precipitates.

Table III. Characterisation of clusters and precipitates after 5 and 600s ageing, respectively.

\begin{tabular}{|c|c|c|c|c|c|c|c|}
\hline \multirow{2}{*}{$\begin{array}{c}\text { Clusters / } \\
\text { precipitates }\end{array}$} & \multicolumn{7}{|c|}{ Composition, at. \% } \\
\hline & $\mathbf{F e}$ & $\mathbf{N i}$ & Mn & $\mathbf{T i}$ & Al & $\begin{array}{c}r_{\mathrm{G}}, \mathbf{n m} / \\
\text { xyz precipitates }\end{array}$ & $\begin{array}{c}\text { No. ions per } \\
\text { cluster/morphology }\end{array}$ \\
\hline$\underline{M n+F e}$ & $0-18$ & $0-12.5$ & $65-100$ & - & - & $1.0 \pm 0.2$ & $20-146$ \\
\hline \multirow{3}{*}{ Ti+Al-rich } & $25-36$ & $3-18$ & - & $16-39$ & $17-47$ & $1.4 \pm 0.3$ & $28-441$ \\
\hline & $2-24$ & $0-22$ & - & $16-75$ & $14-72$ & $1.1 \pm 0.2$ & $22-177$ \\
\hline & 0 & $0-11$ & - & $18-80$ & $21-74$ & $0.8 \pm 0.1$ & $20-62$ \\
\hline$(\mathrm{Ni}, \mathrm{Fe})_{3} \mathrm{Ti}$ & $9 \pm 3$ & $60 \pm 3$ & $1.7 \pm 0.6$ & $22 \pm 2$ & $3.1 \pm 0.6$ & $\begin{array}{l}\sim 9 \times 3 \times 16 \\
\sim 9 \times 8 \times 14 \\
\end{array}$ & $\begin{array}{c}\text { plate-like } \\
\text { rod-like }\end{array}$ \\
\hline$(\mathrm{Ni}, \mathrm{Fe})_{3}(\mathrm{Al}, \mathrm{Mn})$ & $27 \pm 5$ & $40 \pm 6$ & $10 \pm 4$ & $2 \pm 1$ & $17 \pm 3$ & $\sim 4 \times 4 \times 5$ & spheroidal \\
\hline
\end{tabular}

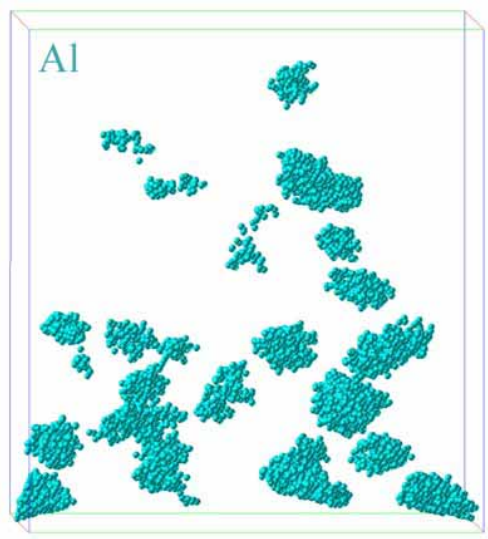

a)

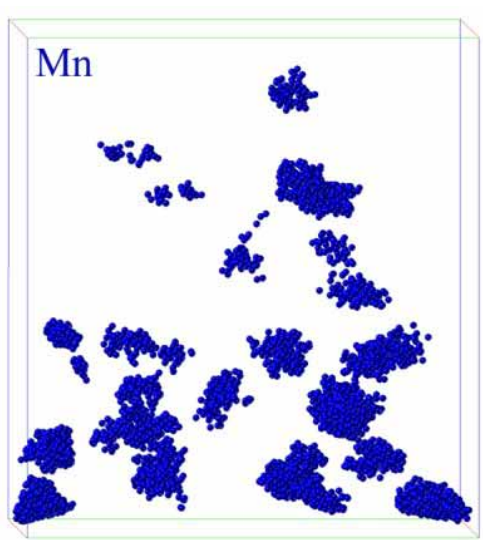

b)

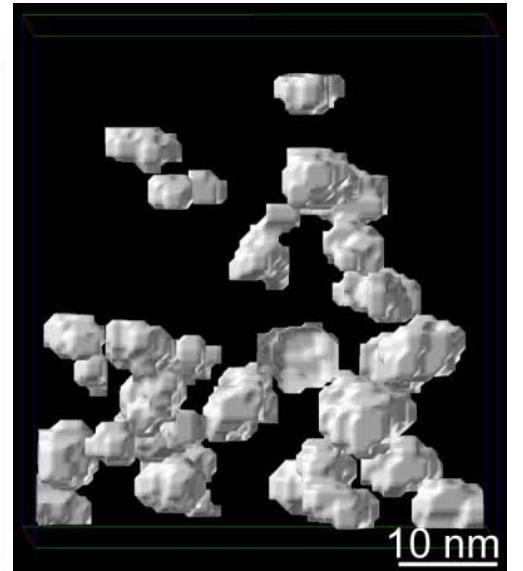

c)

Fig. 3. $\mathrm{Al}$ (a) and $\mathrm{Mn}$ (b) atom maps with corresponding $30 \%(\mathrm{Al}+\mathrm{Mn})$ iso-concentration surfaces showing formation of $(\mathrm{Fe}, \mathrm{Ni})_{3}(\mathrm{Mn}, \mathrm{Al})$ particles after $600 \mathrm{~s}$ ageing at $550^{\circ} \mathrm{C}$.

After 600s ageing in addition to spherical precipitates, complex arrangements of plate-shaped and rod-like particles were clearly visible (Fig. 4). The selected volume analysis of these precipitates has shown that their composition is close to $(\mathrm{Ni}, \mathrm{Fe})_{3} \mathrm{Ti}$ (Table III). It could be suggested that $\mathrm{Ti}+\mathrm{Al}$-rich clusters together with substrucure were preferential nucleation sites for this precipitation. Based on TEM data, there was a long standing debate regarding the exact shape of $\mathrm{Ni}_{3} \mathrm{Ti}$ precipitates in maraging steels being plate-like [16], needlelike [23-25] or rod-like [24,26]. As we now could conclude, both plate and rod morphologies of these precipitates co-exist at certain stages of decomposition. However, our atom probe tomography (APT) data also indicates that with further coarsening both type of precipitates, e.g. $(\mathrm{Ni}, \mathrm{Fe})_{3} \mathrm{Ti}$ and $(\mathrm{Ni}, \mathrm{Fe})_{3}(\mathrm{Al}, \mathrm{Mn})$, tend to exhibit a predominantly rod-like morphology.

\section{Conclusions}

It has been shown that atom probe tomography is a powerful technique which allows complete chemical and 3Dspatial information on nanoscale features in steels to be obtained. The evolution from clustering to precipitation could be followed using APT, as was highlighted using TRIP and maraging steels as examples. However, some deficiencies of APT are noted and care needs to be taken when interpreting results for the features with the sizes about $r_{\mathrm{G}}=1 \mathrm{~nm}$.

\section{Acknowledgement}

The authors acknowledge partial support from the Australian Research Council. The authors are also grateful for technical assistance from the AMMRF at the University of Sydney and the Monash Centre for Electron Microscopy. 


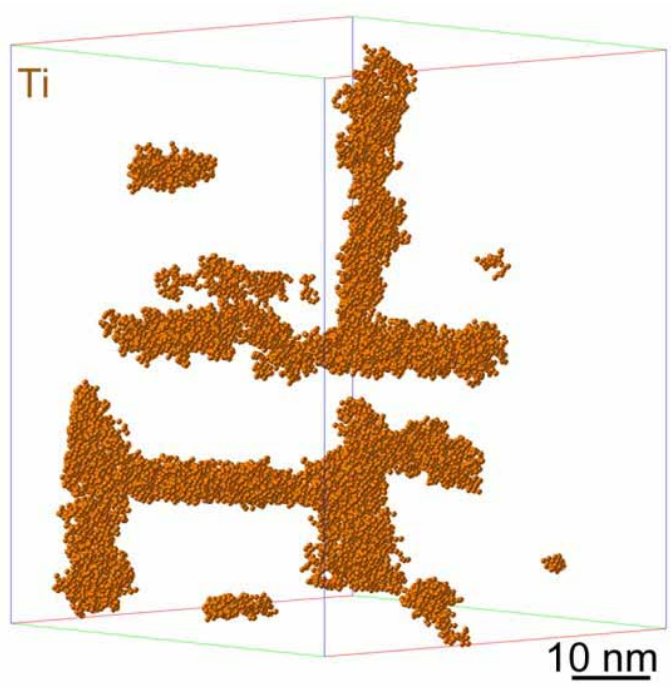

a)

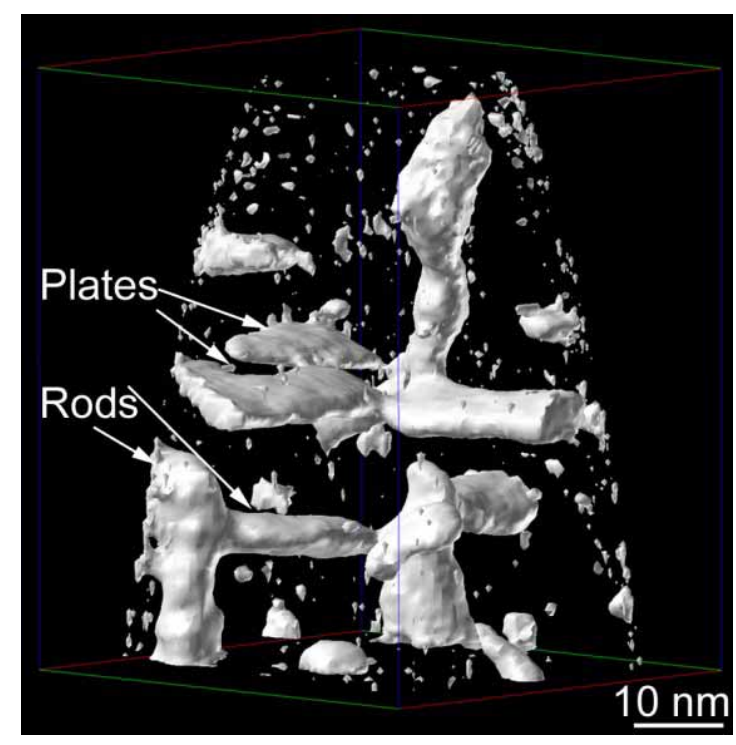

b)

Fig. 4. Ti map (a) and $40 \%(\mathrm{Ni}+\mathrm{Ti})$ iso-concentratin surfaces (b) showing formation of predominantly $(\mathrm{Fe}, \mathrm{Ni})_{3} \mathrm{Ti}$ precipitates in martensite after $600 \mathrm{~s}$ ageing at $550^{\circ} \mathrm{C}$. All other atoms removed by maximum separation method in a).

\section{References}

[1] T.F. Kelly, P.P. Camus, D.J. Larson, L.M. Holzman, S.S. Bajikar, U.S. Patent, 1995, Serial No. 08/272, p. 204.

[2] M.K. Miller, Atom Probe Tomography, in Handbook of Microscopy for Nanotechnology, edited by Nan Yao and Z.L. Wang (Kluwer Academic Press, New York, 2005) p. 742

[3] M.K. Miller, Microsc. Res. Techn, 69, 359 (2006)

[4] G.R. Speich, W.C. Leslie, Metall. Trans. 3, 1043 (1972)

[5] G. Krauss, Steels: Processing, Structure, and Performance (ASM International, Ohio, USA, 2005) p. 327.

[6] L.J. Baker, S.R. Daniel, J.D. Parker, Mater. Sci. Tech. 18, 355 (2002)

[7] B.C. De Cooman, Curr. Opin. Solid St. Mater. Sci. 8, 285 (2004)

[8] T. Waterschoot, A.K. De, S. Vandeputte and B.C. De Cooman, Metall. Trans. 34A, 781 (2003).

[9] I.B. Timokhina, E.V. Pereloma, P.D. Hodgson, Mater. Sci. Forum 539-547, 4315 (2007)

[10] I.B. Timokhina, M. Ryan, M.K. Miller, E.V. Pereloma, Iron and Steel, Suppl. 40, 744 (2005)

[11] I.B. Timokhina, P.D. Hodgson, E.V. Pereloma: Metall. Mater. Trans., 38A, 2442 (2007)

[12] E.V. Pereloma, K.F. Russell, M.K. Miller, I.B. Timokhina, Scripta Mater., 58, 1078 (2008)

[13] I.B. Timokhina, P.D. Hodgson, S.P. Ringer, R.K. Zheng, E.V. Pereloma, Steel Research Int. 80, 506 (2009)

[14] E.V. Emchenko-Rybko, S.P. Oshkaderov, R.V. Televich, G. Ziss, Phys Metals, 6, 495 (1985)

[15] V.G. Gavrilyuk, E.V. Emchenko-Rybko, V.M. Nadutov, S.P. Oshkaderov, R.V. Televich, Phys Metals, 9, 191 (1990)

[16] A. Shekhter, H.I. Aaronson, M.K. Miller, S.P. Ringer, E.V Pereloma, Metall. Mater. Trans. 35A, 973 (2004)

[17] E.V Pereloma, A. Shekhter, M.K. Miller, S.P. Ringer, Acta Mater. 52, 5589 (2004)

[18] M.K. Miller, Atom Probe Tomography (Kluwer, Academic/ Plenum Press, New York, 2000)

[19] E.V. Pereloma, I.B. Timokhina, K.F. Russell, M.K. Miller, Scripta Mater. 54, 471 (2006)

[20] A.M. Sherman, G.T. Eldis, M. Cohen, Metall. Trans. 14A, 995 (1983)

[21] E. Pereloma, M.K. Miller, I.B. Timokhina, Metall. Mater. Trans. (2008)

[22] Y.M. Kim, C.D. Yim, B.S. Yum, Scripta Mater. 57, 691 (2007)

[23] R.D. Garwood, R.D. Jones, J Iron Steel Inst. 204, 512 (1966)

[24] Y. He, K. Yang and W. Sha, Metall. Mater. Trans. 36A, 2273 (2005)

[25] S-J. Kim, C.M. Wayman, Mater. Sci. Eng. 128A, 217 (1990)

[26] K. Vasudevan, S.J. Kim, C.M. Wayman, Metall. Trans. 21A, 2655 (1990) 